\title{
Evaluation of the Reinforcing Strength of Phendimetrazine Using a Progressive-Ratio Schedule of Reinforcement in Rhesus Monkeys
}

\author{
Molly Minkiewicz, Paul W. Czoty, Bruce E. Blough, and Michael A. Nader \\ Department of Physiology and Pharmacology, Wake Forest School of Medicine, Winston-Salem, North Carolina (M.M., P.W.C., \\ M.A.N.) and Discovery Sciences, Research Triangle Institute, Research Triangle Park, North Carolina (B.E.B.)
}

Received January 2, 2020; accepted April 1, 2020

\begin{abstract}
Stimulant abuse is a persistent public health problem with no Food and Drug Administration-approved pharmacotherapy. Although monoamine-releasing drugs such as $d$-amphetamine can decrease cocaine self-administration in human and animal laboratory studies, their potential for abuse limits clinical utility. "Abuse-deterrent" formulations of monoamine releasers, such as prodrugs, hold greater clinical promise if their abuse potential is, as theorized, lower than that of cocaine. In these studies, we determined the reinforcing strength of phendimetrazine (PDM), a prodrug for the amphetamine-like monoamine releaser phenmetrazine; both drugs have been shown to decrease cocaine self-administration in laboratory animals. To date, no study has directly compared PDM (Schedule III) with cocaine (Schedule II) under progressive-ratio (PR) schedules of reinforcement, which are better suited than fixed-ratio schedules to directly compare reinforcing strength of drugs. Dose-response curves for cocaine (saline, $0.001-0.3 \mathrm{mg} / \mathrm{kg}$ per injection) and PDM $(0.1-1.0 \mathrm{mg} / \mathrm{kg}$ per injection) were generated in six cocaine-experienced male rhesus monkeys during 4-hour sessions with a 20-minute limited
\end{abstract}

hold (LH). Under these conditions, the maximum number of injections was not significantly different between cocaine and PDM. The reinforcing strength of doses situated on the peaks of the cocaine and PDM dose-effect curves were redetermined with a 60-minute LH. The mean number of injections increased for both drugs, but not for saline. Cocaine presentations resulted in significantly higher peak injections than PDM with a 60-minute $\mathrm{LH}$, which is consistent with the lower scheduling of PDM. These results support PDM as Schedule III and highlight the importance of schedule parameters when comparing reinforcing strength of drugs using a PR schedule of reinforcement.

\section{SIGNIFICANCE STATEMENT}

One strategy for reducing cocaine use is to identify a treatment that substitutes for cocaine but has lower abuse potential. In a rhesus monkey model of drug abuse, this study compared the reinforcing strength of cocaine and phendimetrazine, a drug that has been shown to decrease cocaine use in some studies.

\section{Introduction}

Substance abuse continues to be a major public health problem, costing $>\$ 700$ billion annually in the United States alone (Volkow and Morales, 2015), with an estimated $>5.5$ million past-year cocaine users, $\sim 1$ million of whom met the diagnostic criteria for cocaine use disorder (CUD; https://www. samhsa.gov/data/). No medications are currently approved by the Food and Drug Administration for treating CUD. The view that developing an agonist pharmacotherapy to treat CUD will significantly improve treatment outcomes is supported by results from treatment of opioid and tobacco use disorders (e.g., Cahill et al., 2013; Ayanga et al., 2016).

Agonist pharmacotherapies have pharmacological effects similar to the abused drug and may reduce its reinforcing effects and alleviate withdrawal symptoms (Herin et al., 2010;

This work was supported by the National Institutes of Health [Grant P50 DA06634]

https://doi.org/10.1124/jpet.120.264952.
Negus and Banks, 2013). One potential limitation of this approach is that the medication itself may have abuse potential. Laboratory animal models can provide significant insight in this regard. For example, clinical and preclinical studies have consistently demonstrated that $d$-amphetamine reduces the reinforcing and subjective effects of cocaine (e.g., Grabowski et al., 2001; Negus and Mello, 2003; Chiodo and Roberts, 2009; Rush et al., 2009; Czoty et al., 2010, 2011, 2016b). Clearly, however, the potential of amphetamines as pharmacotherapies for CUD is limited due to their high abuse potential (e.g., Kollins, 2008; see Negus and Henningfield (2015)). Thus, approaches have been sought that maintain the clinically desirable effects of monoamine releasers, but with reduced or absent abuse potential. One alternative is a prodrug that is itself relatively inert if injected or insufflated but is converted to an active compound after administration (Huttunen et al., 2011; Rush and Stoops, 2012). Examples include lisdexamfetamine (Vyvanse; Pennick, 2010) and phendimetrazine (PDM), which is converted in the liver to phenmetrazine, an amphetamine-like releaser of dopamine

ABBREVIATIONS: CUD, cocaine use disorder; FR, fixed ratio; LH, limited hold; LH20, 20-minute limited hold; LH60, 60-minute limited hold; PDM, phendimetrazine; PR, progressive ratio. 
and norepinephrine (Rothman et al., 2002; Negus et al., 2009; Banks et al., 2013b). In laboratory animals, PDM has demonstrated characteristics desirable of an agonist pharmacotherapy, including a relatively slow onset and long duration of action, generalization to the discriminative-stimulus effects of cocaine, and, importantly, the ability to reduce cocaine selfadministration (Negus et al., 2009; Banks et al., 2011, 2013a,b,c,d, 2016; Czoty et al., 2015, 2016a).

Relatively few studies have examined the abuse potential of PDM in laboratory animals. Griffiths et al. (1979) studied PDM self-administration under a fixed-ratio (FR) schedule of 160 responses in baboons in which a 3-hour timeout followed each injection and sessions lasted 24 hours. Under these conditions, PDM was self-administered, and peak injections were similar to cocaine. In contrast, Corwin et al. (1987) reported that PDM did not function as a reinforcer under an FR reinforcement schedule of 10 responses in monkeys, six of seven of which were experimentally naïve. In that experiment, there was no timeout, and sessions lasted 2 hours.

Determining that a putative pharmacotherapy for CUD lacks (or has low) abuse potential is a critical step in its path to clinical use. To understand the abuse potential of PDM relative to cocaine, it is important to compare PDM and cocaine under identical experimental conditions and appropriate schedules of reinforcement (Nader, 2016). In the present study, we assessed the reinforcing effects of a range of doses of cocaine and PDM in rhesus monkeys responding under a progressive-ratio (PR) schedule of reinforcement. We chose a PR schedule because in addition to determining whether a drug serves as a reinforcer, a PR schedule can also be used to compare the degree to which drugs serve as reinforcers, termed the "reinforcing strength" of the drugs. With regard to novel pharmacotherapies for CUD or other abused drugs, this type of information is more informative to the process of assigning the drug to a schedule as required under the 1971 Controlled Substances Act than simply knowing whether it can function as a reinforcer (see Nader (2016)). Moreover, comparing the reinforcing strength of drugs under diverse conditions can help to draw conclusions about the influence that schedule of reinforcement and parameters have on results of specific studies. PDM is Schedule III but has never been directly compared with cocaine under PR schedules of reinforcement.

In the present study, we compared self-administration of cocaine and PDM under a PR schedule in which the 4-hour session ended when 20 minutes passed without an injection [a 20-minute limited hold (LH; LH20)]. Katz (1990) noted that different PR procedures may not be strictly comparable, so we compared the reinforcing strength of doses of both drugs that were situated on the peaks of the two dose-effect curves when the LH was increased to 60 minutes (LH60). This manipulation is also of relevance because as a prodrug, PDM has a longer duration of action, and thus effects may be more evident when more time is permitted to pass before the session terminates.

\section{Materials and Methods}

Subjects. Six individually housed adult male rhesus monkeys (R1604, R-1712, R-1717, R-1741, R-1743, R-1744) were used in these studies. Monkeys weighed between 8 and $12 \mathrm{~kg}$ and had several years' experience self-administering cocaine. Monkeys had unlimited access to water in their home cage and received fresh fruit or vegetables, peanuts, and primate chow (Laboratory Diet Chow, Purina, St Louis, MO) daily. To prevent development of obesity and cardiovascular/ metabolic problems, monkeys were not fed ad libitum. They were also not maintained at a "target weight" set to be an arbitrary percentage below free-feeding weight because the latter can change with age and other factors, and we did not plan to remove monkeys from the study for periodic redetermination of free-feeding weights. Instead, monkeys were weighed weekly and fed enough food daily (Purina Monkey Chow and fresh fruit and vegetables) to maintain a healthy body weight and appearance as determined by daily inspection and periodic veterinary examinations. Animal housing and handling and all experimental procedures were performed in laboratory animals and were approved by the Animal Care and Use Committee of Wake Forest University. Environmental enrichment was provided as outlined in the Animal Care and Use Committee of Wake Forest University Non-Human Primate Environmental Enrichment Plan.

Surgical Procedure. Each monkey was surgically prepared with a chronic indwelling venous catheter into a major vein (femoral, internal, or external jugular) and subcutaneous vascular port (Access Technologies, Skokie, IL) using aseptic surgical procedures. Anesthesia was induced with ketamine $(10 \mathrm{mg} / \mathrm{kg}$ i.m.) and maintained with ketamine supplements throughout the procedure. The distal end of the catheter was passed subcutaneously to a point slightly off the midline of the back, where an incision was made. The end of the catheter was attached to a vascular port that was placed in a subcutaneous pocket formed by blunt dissection.

Apparatus. Each monkey was fitted with an aluminum collar (Primate Products, Redwood City, CA) and trained to sit calmly in a standard primate chair (Primate Products). Before each session, the monkey was placed into a primate chair, transported to a separate room, and placed into a ventilated, sound-attenuating chamber $(1.5 \times$ $0.74 \times 0.76 \mathrm{~m}$; Med Associates, East Fairfield, VT). Inside the chamber two photo-optic switches ( $5 \mathrm{~cm}$ wide) were located on one side with a horizontal row of three stimulus lights $14 \mathrm{~cm}$ above each switch. One of these switches, counterbalanced across monkeys, was used to selfadminister drugs. An infusion pump (Cole-Palmer, Inc., Chicago, IL) was located on the top of the chamber. Prior to being placed in the chamber, the area around each subjects' port was scrubbed with povidone-iodine solution, USP $10 \%$. This solution was wiped off with $70 \%$ isopropyl alcohol, and the povidone-iodine solution was reapplied in a circle, motioning away from the port and sterilized area; it was then allowed to sit on the skin for approximately 5 minutes to dry prior to administration of any solution. After all self-administration sessions, each monkey's catheter was flushed with heparinized saline (100 U/ml) to prevent clotting.

Drug Self-Administration. Daily sessions began at approximately 8:00 AM. At the start of the session, the white light above the drug switch was illuminated, and monkeys responded under a PR schedule of reinforcement. Under this schedule, emission of 20 responses resulted in the first i.v. injection of cocaine, extinguishing of the white light, and a 10-second timeout during which the red light was illuminated. The response requirement for subsequent injections was determined by the equation used by Richardson and Roberts (1996): response requirement $=\left[5 \times e^{(\mathrm{R} \times 0.2)}\right] \times 5$, where $e$ is the mathematical constant and $\mathrm{R}$ is equal to the reinforcer number. For the present studies, the first response requirement ( 20 responses) corresponds to the eighth value given by this equation and was followed by $25,32,40,50,62,77,95,117,144,177,218$, 267, 328, 402, 492, 602, etc. Sessions ended when 20 minutes elapsed without an injection $(\mathrm{LH})$ or the total session duration reached 4 hours.

Initially, injections of $0.03 \mathrm{mg} / \mathrm{kg}$ per injection cocaine were made available for at least five sessions and until responding was stable (number of injections $\pm 20 \%$ of a 3-day mean with no upward or downward trend). Next, dose-effect curves were constructed by substituting saline or different doses of cocaine $(0.001-0.3 \mathrm{mg} / \mathrm{kg}$ per injection) or PDM (0.1-1.0 mg/kg per injection) for $0.03 \mathrm{mg} / \mathrm{kg}$ per injection until responding stabilized. After evaluating saline and each drug dose, responding was again maintained by $0.03 \mathrm{mg} / \mathrm{kg}$ per injection 
cocaine, and stability was achieved before another drug dose was studied. Cocaine dose-response curves were determined first, and the order of dose presentation was quasi-randomized across subjects. Prior to studying PDM, saline was substituted for $0.03 \mathrm{mg} / \mathrm{kg}$ per injection cocaine. After completing the cocaine and PDM dose-response curves, the LH was increased to 60 minutes, and the reinforcing effects of saline and doses of cocaine and PDM that were situated at the peak of the respective dose-effect curves were redetermined. In some animals, multiple doses were reexamined under the LH60 condition.

Data Analysis. The primary dependent variables were the total number of injections delivered and total session time (maximum of 14,400 seconds) during availability of saline and each drug dose, calculated as the mean of the last three sessions of stable responding. In each subject, a dose was defined as reinforcing if the number of injections delivered during its availability fell outside the $95 \%$ confidence intervals of the mean number of injections delivered during saline availability. To compare maximum reinforcing strength across different limited hold values (LH20 vs. LH60), mean injections delivered during availability of saline and the peak reinforcing doses of cocaine and PDM were analyzed using a repeated measures twoway ANOVA with drug and $\mathrm{LH}$ value as factors, followed by post hoc Sidak's multiple comparisons $t$ tests. Data are shown for number of injections received under each drug condition. To examine the impact of $\mathrm{LH}$ on session time, $t$ tests were conducted for data obtained with saline and the peak doses of cocaine and PDM. In all cases, differences were considered significant when $P<0.05$.

Drugs. (-)Cocaine $\mathrm{HCl}$ was supplied by the National Institutes of Health National Institute on Drug Abuse (Bethesda, MD) and dissolved in sterile $0.9 \%$ saline. (+)PDM fumarate was synthesized at Research Triangle Institute (Research Triangle Park, NC) and dissolved in sterile $0.9 \%$ saline.

\section{Results}

Under the LH20 condition, responding maintained by cocaine and PDM was generally characterized as an inverted-U-shaped function of dose. Several doses of cocaine and PDM resulted in significantly higher number of injections than saline and therefore had reinforcing effects in all animals (Fig. 1, open symbols). Cocaine was more potent than PDM in all monkeys; the peak number of injections was not different between the two drugs. Under these conditions, sessions expired before the maximum session length (14,400 seconds) was reached (Table 1). Session length was significantly longer when the peak dose of cocaine and PDM were studied, compared with saline $(P<0.01$; Table 1$)$.

When the peak reinforcing doses of cocaine were reexamined under the LH60 condition, monkeys self-administered a greater number of injections. When the reinforcing strength of PDM doses that were situated on the peak of the LH20 curves were redetermined under LH60 conditions (Fig. 1, filled symbols), four monkeys self-administered a greater number of injections, whereas the reinforcing strength of that dose did not change in two monkeys. When the number of injections of saline and peak doses of cocaine and PDM were compared across the LH20 and LH60 conditions (Fig. 2), there was a significant main effect of $\operatorname{drug}\left(\mathrm{F}_{2,15}=24.37, P<0.001\right)$ and a main effect of $\mathrm{LH}$ value $\left(\mathrm{F}_{1,14}=18.77\right)$ with no significant interaction. Post hoc comparisons indicated that, as expected, peak injections of both cocaine and PDM differed significantly from saline. At LH60, injections of peak doses of cocaine and PDM also were significantly different. In addition, post hoc testing determined that changing the LH from 20 to 60 minutes increased the number of selfadministered injections of both cocaine and PDM, but not
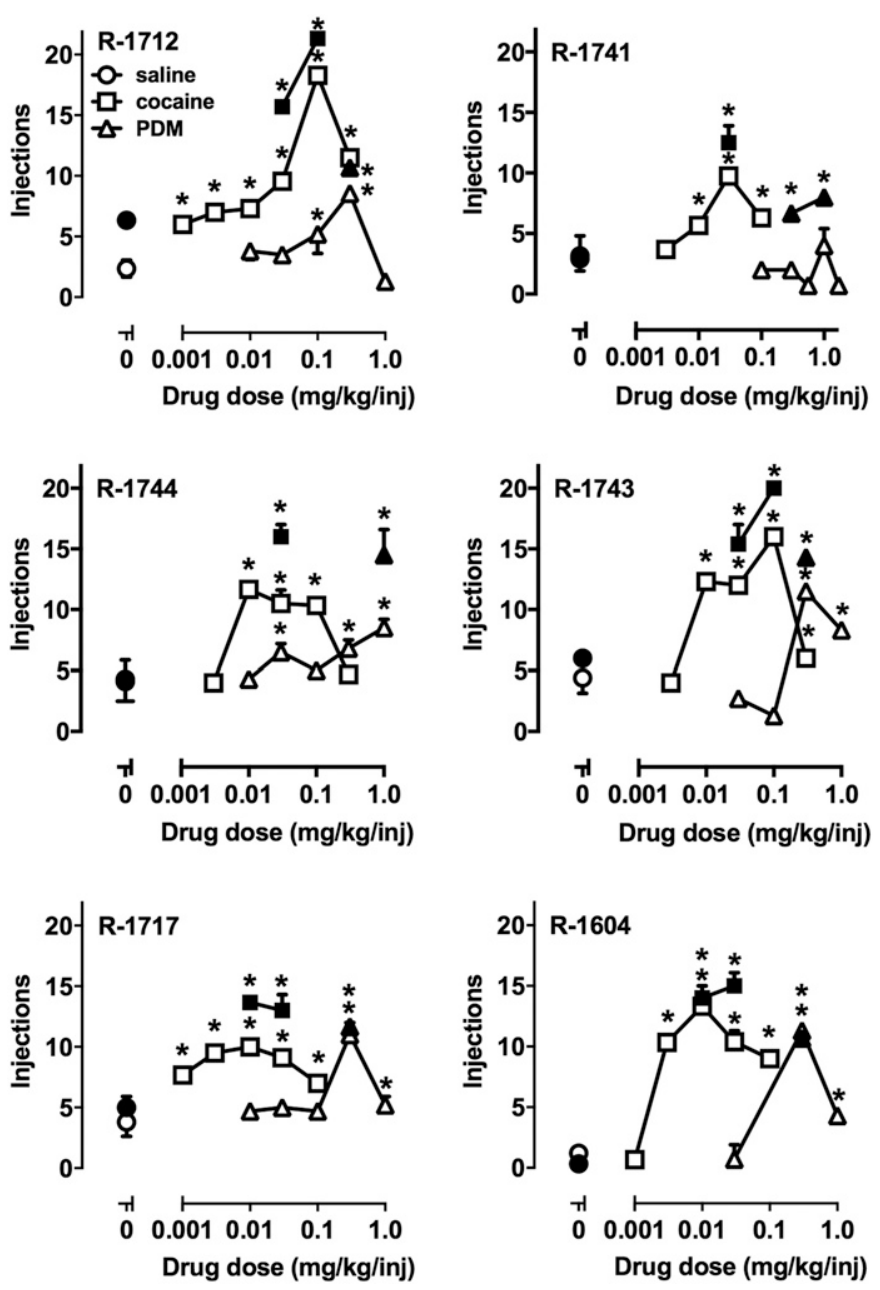

Fig. 1. Self-administration of saline, cocaine and PDM in six rhesus monkeys at two LH values. Abscissae, available dose. Ordinates, number of injections delivered. Open symbols, LH20. Filled symbols, LH60. * indicates the point was outside the $95 \%$ confidence intervals of the average number of saline injections delivered at the same LH value.

saline. Despite the increases in injections, session length was not significantly different between LH20 and LH60 for cocaine or PDM (Table 1).

\section{Discussion}

A critical step in the Food and Drug Administration approval of any new medication is assessment of its abuse potential; this is particularly important for putative treatments for substance use disorders. Prodrugs, such as PDM, that are metabolized to monoamine releasers have been shown to decrease the abuserelated effects of cocaine in laboratory animals (Negus et al., 2009; Banks et al., 2011, 2013a,b,c,d, 2016; Czoty et al., 2015, 2016a). Although the prodrug strategy is considered an "abusedeterrent" approach, a direct assessment of abuse potential remains of importance. This is particularly true because PDM has been shown to inhibit the dopamine transporter (Solis et al., 2016) and to share discriminative-stimulus effects with cocaine (Banks et al., 2013b).

Conflicting conclusions have arisen from the two previous assessments of the abuse potential of PDM in monkey models. This may be due in part to the use of different experimental 
TABLE 1

Session length (seconds) when saline and the peak doses of cocaine and PDM were studied ${ }^{a}$

\begin{tabular}{|c|c|c|c|c|c|c|}
\hline \multirow{2}{*}{ Subject } & \multicolumn{2}{|c|}{ Saline } & \multicolumn{2}{|c|}{ Cocaine } & \multicolumn{2}{|c|}{ PDM } \\
\hline & LH20 & LH60 & LH20 & LH60 & LH20 & LH60 \\
\hline R-1712 & $1264.44 \pm 33.6$ & $10,444.44 \pm 482.3$ & $7854.71 \pm 1940.5$ & $13,258.60 \pm 291.9$ & $2213.47 \pm 520.6$ & $9625.00 \pm 3271.2$ \\
\hline R-1741 & $1245.00 \pm 356.8$ & $3727.00 \pm 14.0$ & $4438.00 \pm 355.8$ & $5459.00 \pm 804.2$ & $2937.00 \pm 338.2$ & $5494.33 \pm 836.5$ \\
\hline R-1744 & $1778.00 \pm 640.0$ & $7520.00 \pm 5961.9$ & $3539.33 \pm 527.4$ & $9761.00 \pm 4079.4$ & $3359.33 \pm 507.7$ & $11,573.00 \pm 3763.6$ \\
\hline R-1743 & $1913.89 \pm 1265.5$ & $7751.11 \pm 2535.7$ & $7050.82 \pm 1003.5$ & $13,498.53 \pm 265.9$ & $3322.42 \pm 584.6$ & $9712.40 \pm 3253.6$ \\
\hline R-1717 & $1730.67 \pm 472.0$ & $5065.00 \pm 902.8$ & $2333.33 \pm 219.2$ & $5500.67 \pm 894.9$ & $2693.67 \pm 650.0$ & $6707.00 \pm 635.7$ \\
\hline $\mathrm{R}-1604$ & $1189.67 \pm 501.7$ & $3659.67 \pm 103.3$ & $4314.00 \pm 64.1$ & $10,187.00 \pm 2018.2$ & $4372.67 \pm 336.5$ & $6764.00 \pm 1508.4$ \\
\hline Mean \pm S.E.M. & $1520.28 \pm 143.69$ & $6361.20 \pm 1197.75$ & $4921.70 \pm 945.51$ & $9610.80 \pm 1586.27$ & $3149.76 \pm 328.58$ & $8312.62 \pm 1043.66$ \\
\hline
\end{tabular}

${ }^{a}$ Numbers represent means \pm S.D. for the last three sessions of that condition; maximum session length was $14,400 \mathrm{~s}$.

conditions. Griffiths et al. (1979) studied PDM under an FR 160 schedule of reinforcement in 24-hour sessions in which 3 hours elapsed between injections. PDM functioned as a reinforcer in baboons under these conditions. In contrast, PDM did not function as a reinforcer in rhesus monkeys under an FR 10 schedule of reinforcement (Corwin et al., 1987). A potentially critical difference is that the Corwin et al. study used a much shorter session length ( 2 hours), with no timeout between injections. Thus, the conflicting results might be explained by the fact that, as a prodrug which requires conversion to an active form, a longer session time may be needed for the onset of reinforcing effects of PDM. A related point is that neither previous study used a reinforcement schedule better suited for determining whether PDM had lower abuse potential than cocaine (Nader, 2016). The present study was thus designed to compare the reinforcing strength of cocaine and PDM under a PR schedule of reinforcement. Our hypothesis, based on the results of Griffiths et al. (1979) and Corwin et al. (1987), was that PDM would function as a reinforcer, with reinforcing strength lower than cocaine, as would be suggested by it being classified as Schedule III.

Although the PR schedule is better suited than FR schedules for comparing reinforcing strength of drugs, the parameters (e.g., limited hold, session length) can also impact interpretation of PR data (Katz, 1990). In the present study, complete dose-response curves were determined when the LH was 20 minutes. Under these conditions, both cocaine and PDM functioned as reinforcers. Although cocaine was more

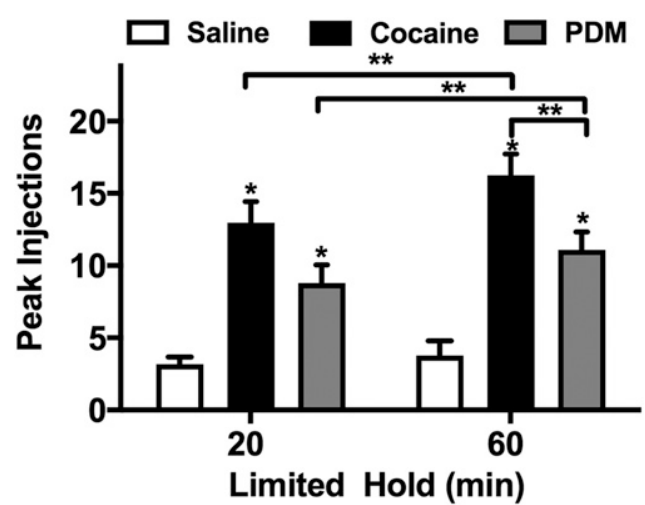

Fig. 2. Mean peak number of injections of saline, cocaine, and PDM at two LH values. Bars represent mean \pm S.E.M. $(n=6) . * P<0.05$ compared with saline at same $\mathrm{LH} .{ }^{* *} P<0.05$ within drug across $\mathrm{LH}$ values, or between drugs within an LH value. Abscissa, limited hold duration. Ordinate, peak number of injections delivered for each drug regardless of the dose. potent in all subjects, the maximum reinforcing strength of the two drugs was, on average, not different at LH20. It should be noted, however, that a clear difference in maximal effectiveness was observed in two of the six subjects (R-1712 and R1741). When we tested the hypothesis that parametric changes would affect outcome, we found that increasing the time that was allowed to elapse before the session ended from 20 to 60 minutes resulted in significant increases in the number of self-administered injections of both cocaine and PDM (at the dose that was maximally reinforcing at LH20), with no change in the number of saline injections delivered. Interestingly, however, the maximum effectiveness of cocaine increased to a greater extent than that of PDM, and a significant difference between the drugs was observed at LH60. These results highlight the influence that session parameters can have on conclusions when the maximum reinforcing strength of two drugs is compared using a PR schedule.

The conclusion of the present study that PDM has abuse potential is consistent with that of Griffiths et al. (1979) and extends those result to indicate that, at some conditions, peak reinforcing effects are similar to those of cocaine. It is also relevant that the present study was conducted in rhesus monkeys, confirming that the difference in results of the Griffiths et al. (1979) and Corwin et al. (1987) studies (which were conducted in baboons and rhesus monkeys, respectively) was not due to species differences. One other difference in experimental design that should be noted is that in the present study and Griffiths et al. (1979), subjects had extensive experience self-administering cocaine, whereas six of eight subjects in the Corwin et al. (1987) study were experimentally naïve. There is a precedent for dopaminergic drugs to function as reinforcers in cocaine-experienced, but not cocaine-naïve monkeys (e.g., Nader and Mach, 1996; Lile et al., 2000; Collins and Woods, 2007).

Although animal models have shown that PDM can decrease cocaine self-administration (Negus et al., 2009; Banks et al., 2011, 2013a,b,c,d, 2016; Czoty et al., 2015, 2016a), human laboratory data indicate that although PDM is well tolerated and reduces some subjective effects of cocaine ("stimulant" and "talkative/friendly"), it does not attenuate most of the positive subjective effects (e.g., "euphoric," "high" or "like drug") or the reinforcing effects of cocaine (Bolin et al., 2016; Stoops et al., 2019). The clinical implication of these results is that despite the ability to reduce cocaine selfadministration in laboratory animals, the potential for abuse may limit the clinical potential of PDM; our goal was to determine whether that abuse potential was lower than cocaine. The present data clearly demonstrate reinforcing 
effects of PDM. Because plasma samples were not collected, whether this is due to reinforcing effects of PDM itself or because PDM is rapidly converted to the monoamine releaser phenmetrazine is not clear. However, previous results from combined behavioral and pharmacokinetic studies indicate that PDM can produce cocaine-like discriminative-stimulus effects within 10 minutes after intramuscular administration, when phenmetrazine levels have not yet begun to rise (Banks et al., 2013b). Pharmacokinetic data showed that PDM plasma levels were highest at 10 and 30 minutes, whereas phenmetrazine plasma levels were lowest at those time points. These data suggest that PDM, the prodrug, was functioning as a reinforcer in the present study. In addition to this primary conclusion, the results highlight the importance of schedule parameters. To fully evaluate the reinforcing strength of drugs, parameters should be incorporated that minimize direct effects (i.e., rate-decreasing) of self-administered drugs.

\section{Acknowledgments}

The authors thank Michael Coller, Jillian Odom, and Susan Nader for assistance with these studies.

\section{Authorship Contributions}

Participated in research design: Minkiewicz, Czoty, Nader.

Conducted experiments: Minkiewicz.

Performed data analysis: Minkiewicz, Czoty.

Wrote or contributed to writing of the manuscript: Minkiewicz, Czoty, Blough, Nader.

\section{References}

Ayanga D, Shorter D, and Kosten TR (2016) Update on pharmacotherapy for treatment of opioid use disorder. Expert Opin Pharmacother 17:2307-2318.

Banks ML, Blough BE, Fennell TR, Snyder RW, and Negus SS (2013a) Effects of phendimetrazine treatment on cocaine vs food choice and extended-access cocaine consumption in rhesus monkeys. Neuropsychopharmacology 38:2698-2707.

Banks ML, Blough BE, Fennell TR, Snyder RW, and Negus SS (2013b) Role of phenmetrazine as an active metabolite of phendimetrazine: evidence from studies of drug discrimination and pharmacokinetics in rhesus monkeys. Drug Alcohol Depend 130:158-166.

Banks ML, Blough BE, and Negus SS (2011) Effects of monoamine releasers with varying selectivity for releasing dopamine/norepinephrine versus serotonin on choice between cocaine and food in rhesus monkeys. Behav Pharmacol 22:824-836.

Banks ML, Blough BE, and Negus SS (2013c) Effects of 14-day treatment with the schedule III anorectic phendimetrazine on choice between cocaine and food in rhesus monkeys. Drug Alcohol Depend 131:204-213.

Banks ML, Blough BE, and Negus SS (2013d) Interaction between behavioral and pharmacological treatment strategies to decrease cocaine choice in rhesus monkeys. Neuropsychopharmacology 38:395-404.

Banks ML, Smith DA, Kisor DF, and Poklis JL (2016) Relationship between discriminative stimulus effects and plasma methamphetamine and amphetamine levels of intramuscular methamphetamine in male rhesus monkeys. Pharmacol Biochem Behav 141:58-65.

Bolin BL, Stoops WW, Sites JP, and Rush CR (2016) Abuse potential of oral phendimetrazine in cocaine-dependent individuals: implications for agonist-like replacement therapy. J Addict Med 10:156-165.

Cahill K, Stevens S, Perera R, and Lancaster T (2013) Pharmacological interventions for smoking cessation: an overview and network meta-analysis. Cochrane Database Syst Rev 34:CD009329.

Chiodo KA and Roberts DC (2009) Decreased reinforcing effects of cocaine following 2 weeks of continuous D-amphetamine treatment in rats. Psychopharmacology (Berl) 206:447-456.

Collins GT and Woods JH (2007) Drug and reinforcement history as determinants of the response-maintaining effects of quinpirole in the rat. $J$ Pharmacol Exp Ther 323:599-605

Corwin RL, Woolverton WL, Schuster CR, and Johanson CE (1987) Anorectics: effects on food intake and self-administration in rhesus monkeys. Alcohol Drug Res 7:351-361.
Czoty PW, Blough BE, Fennell TR, Snyder RW, and Nader MA (2016a) Attenuation of cocaine self-administration by chronic oral phendimetrazine in rhesus monkeys. Neuroscience 324:367-376.

Czoty PW, Gould RW, Martelle JL, and Nader MA (2011) Prolonged attenuation of the reinforcing strength of cocaine by chronic d-amphetamine in rhesus monkeys. Neuropsychopharmacology 36:539-547.

Czoty PW, Martelle JL, and Nader MA (2010) Effects of chronic d-amphetamine administration on the reinforcing strength of cocaine in rhesus monkeys. Psychopharmacology (Berl) 209:375-382.

Czoty PW, Stoops WW, and Rush CR (2016b) Evaluation of the "pipeline" for development of medications for cocaine use disorder: a review of translational preclinical, human laboratory, and clinical trial research. Pharmacol Rev 68:533-562.

Czoty PW, Tran P, Thomas LN, Martin TJ, Grigg A, Blough BE, and Beveridge TJ (2015) Effects of the dopamine/norepinephrine releaser phenmetrazine on cocaine self-administration and cocaine-primed reinstatement in rats. Psychopharmacology (Berl) 232:2405-2414.

Grabowski J, Rhoades H, Schmitz J, Stotts A, Daruzska LA, Creson D, and Moeller FG (2001) Dextroamphetamine for cocaine-dependence treatment: a double-blind randomized clinical trial. J Clin Psychopharmacol 21:522-526.

Griffiths RR, Brady JV, and Bradford LD (1979) Predicting the abuse liability of drugs with self-administration procedures: psychomotor stimulants and hallucinogens. Adv Behav Pharmacol 2:163-208.

Herin DV, Rush CR, and Grabowski J (2010) Agonist-like pharmacotherapy for stimulant dependence: preclinical, human laboratory, and clinical studies. Ann NY Acad Sci 1187:76-100.

Huttunen KM, Raunio H, and Rautio J (2011) Prodrugs--from serendipity to rational design. Pharmacol Rev 63:750-771.

Katz JL (1990) Models of relative reinforcing efficacy of drugs and their predictive utility. Behav Pharmacol 1:283-301.

Kollins SH (2008) A qualitative review of issues arising in the use of psychostimulant medications in patients with $\mathrm{ADHD}$ and co-morbid substance use disorders. Curr Med Res Opin 24:1345-1357.

Lile JA, Morgan D, and Nader MA (2000) First- versus last-session substitution: an evaluation of the reinforcing effects of cocaine and the cocaine analogue 2betapropanoyl-3beta-(4-tolyl)-tropane. Exp Clin Psychopharmacol 8:424-433.

Nader MA (2016) Animal models for addiction medicine: from vulnerable phenotypes to addicted individuals. Prog Brain Res 224:3-24.

Nader MA and Mach RH (1996) Self-administration of the dopamine D3 agonist 7 OH-DPAT in rhesus monkeys is modified by prior cocaine exposure. Psychopharmacology (Berl) 125:13-22.

Negus SS and Banks ML (2013) Medications development for opioid abuse. Cold Spring Harb Perspect Med 3:a012104.

Negus SS, Baumann MH, Rothman RB, Mello NK, and Blough BE (2009) Selective suppression of cocaine- versus food-maintained responding by monoamine releasers in rhesus monkeys: benzylpiperazine, (+)phenmetrazine, and 4benzylpiperidine. J Pharmacol Exp Ther 329:272-281.

Negus SS and Henningfield J (2015) Agonist medications for the treatment of cocaine use disorder. Neuropsychopharmacology 40:1815-1825.

Negus SS and Mello NK (2003) Effects of chronic d-amphetamine treatment on cocaine- and food-maintained responding under a second-order schedule in rhesus monkeys. Drug Alcohol Depend 70:39-52.

Pennick M (2010) Absorption of lisdexamfetamine dimesylate and its enzymatic conversion to d-amphetamine. Neuropsychiatr Dis Treat 6:317-327.

Richardson NR and Roberts DCS (1996) Progressive ratio schedules in drug selfadministration studies in rats: a method to evaluate reinforcing efficacy. $J$ Neurosci Methods 66:1-11.

Rothman RB, Katsnelson M, Vu N, Partilla JS, Dersch CM, Blough BE, and Baumann MH (2002) Interaction of the anorectic medication, phendimetrazine, and its metabolites with monoamine transporters in rat brain. Eur $J$ Pharmacol 447:51-57.

Rush CR and Stoops WW (2012) Agonist replacement therapy for cocaine dependence: a translational review. Future Med Chem 4:245-265.

Rush CR, Stoops WW, and Hays LR (2009) Cocaine effects during D-amphetamine maintenance: a human laboratory analysis of safety, tolerability and efficacy. Drug Alcohol Depend 99:261-271.

Solis E Jr, Suyama JA, Lazenka MF, DeFelice LJ, Negus SS, Blough BE, and Banks ML (2016) Dissociable effects of the prodrug phendimetrazine and its metabolite phenmetrazine at dopamine transporters. Sci Rep 6:31385.

Stoops WW, Strickland JC, Alcorn JL III, Hays LR, Rayapati AO, Lile JA, and Rush CR (2019) Influence of phendimetrazine maintenance on the reinforcing, subjective, performance, and physiological effects of intranasal cocaine. Psychopharmacology (Berl) 236:2569-2577.

Volkow ND and Morales M (2015) The brain on drugs: from reward to addiction. Cell 162:712-725.

Address correspondence to: Dr. Michael A. Nader, Department of Physiology and Pharmacology, Wake Forest School of Medicine, 546 NRC, Medical Center Boulevard, Winston-Salem, NC 27157-1083. E-mail: mnader@ wakehealth.edu 